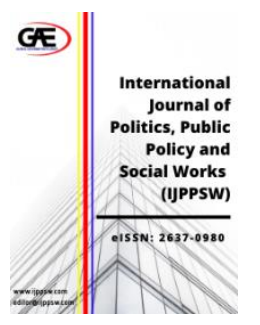

\author{
INTERNATIONAL JOURNAL OF \\ POLITICS, PUBLICS POLICY \\ AND SOCIAL WORKS \\ (IJPPSW) \\ wWw.ijppsw.com
}

\title{
THE SOUTH KOREAN CYBER POLICY IN PROMOTING ACTIVE INTERNET USERS AND ITS VULNERABILITIES IN CYBER THREATS
}

\author{
Hanis Shaheera
}

1 Department of Strategic Studies, Universiti Pertahanan Nasional Malaysia, Malaysia

Email: hanis@upnm.edu.my

Article Info:
Article history:
Received date: 26.08 .2020
Revised date: 01.10 .2020
Accepted date: 30.10 .2020
Published date: 02.12 .2020
To cite this document:
Shaheera, H. (2020). The South
Korea Cyber Policy in Promoting
Active Internet Users and Its
Vulnerabilities in Cyber Threats.
International Journal of Politics,
Publics Policy and Social Works, 2
(7), 11-23.

DOI: $10.35631 / \mathrm{IJPPSW} .27002$.

This work is licensed under CC BY 4.0

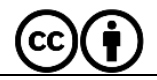

\begin{abstract}
:
The world is now entering the 4th Industrial Revolution (IR4) and South Korea is the example that accepted the cutting-edge evolution as it is a country with the most wired in the world. Hence, this study intends to explore the initiatives taken by the government of South Korea in succeeding to encourage and expand internet users among South Korean by implementing an auxiliary cyber policy. This study will implement a qualitative method by focusing on the case study of South Korea. The researcher intends to examine the cyber policy made by the South Korean government and its effect on the increasing internet usage among South Korean. The findings show that there are demographic factors in influencing internet users and mechanisms taken by the government by collaborating with private agencies in influencing South Korean through media platforms about the benefits of using the internet as part of daily life despite its vulnerability in cybercrimes.
\end{abstract}

Keywords:

Cyber Security, Cyber Policy, Security Studies, South Korea, Cybercrimes

\section{Introduction}

South Korea is located in East Asia and surrounded by major powers such as China, Japan and bordered with North Korea. The geographical factor plays an important role in the government of South Korea in managing cyber threats issues; especially from North Korea. The IR4 is known to be a digital revolution where it creates blurring lines between the physical, digital, and biological sphere which is characterized by the fusion of technologies (Schwab, 2016). This revolution occurred due to the rapid information revolution through digital, information technology (IT), and data throughout the globe which affect social and 


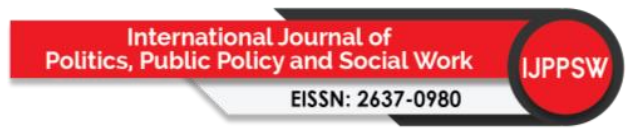

Volume 2 Issue 7 (December 2020) PP. 11-23 DOI: 10.35631/IJPPSW.27002 economic development. Hence, one of the cores related to the IR4 is security and conflicts; in which cybersecurity falls under this core.

The history of South Korea involved in the internet can be traced back to 1982 where the internet service has been introduced and remarked the establishment of System Development Network. This internet service included the service for commercializing the nation's economic purpose, email system, information search, and others. The commercialization took place in this country, thus, creating an expansion growth in 1994. During the year 2013, South Korea has demonstrated its capability by reaching more than 40 mil internet users and becoming the first to launch Wireless Broadband (WiBro) and High-Speed Downlink Packet Access (HSDPA) for commercial services. Therefore, realizing the advantages of the IR4 trends, the South Korean government took responsibility by planning long term comprehensive plans of intelligence information policy society (ICT \& KISA, 2018).

The South Korean government is supportive of encouraging its citizens in using the internet because it is believed that modes of communication have a crucial after effect towards the people. Besides the internet expansion has increased dramatically, further manifesting its social networking status and power around the world. Therefore, countries are competing in advancing their technologies to gain their national objectives, to get more power, and to ensure their national security at the best standard.

This paper intends to analyze the South Korean government in articulates cyber policy to implement initiatives in promoting internet usage among their people. This study is also intending to explore the vulnerabilities of cyber threats towards South Korean since this country is known to have the capability in internet infrastructure, fastest internet speed, and highest internet penetration in the world.

\section{Methodology}

This research adopts a qualitative method. It uses a comprehensive literature review to explains the phenomena based on thorough observation. The literature review collected by this study is divided into three categories; first, the cyber policy in South Korea, second, the data for internet users in South Korea, and last, the cyberattacks capability and cases in South Korea. This study uses a conceptual framework to explain this research. Table 1 shows that the South Korean government initiatives in promoting internet users by articulate cyber policy and cooperating with the private sector in developing stability in network technologies and make use of cyberspace to achieve its national objectives. National objectives can be classified into three aspects; politics, defense, and the economy.

\section{Table 1: The Correlation between South Korean Government and Private Sector} Initiatives in Promoting Internet Users with the Vulnerabilities to Cyberattacks

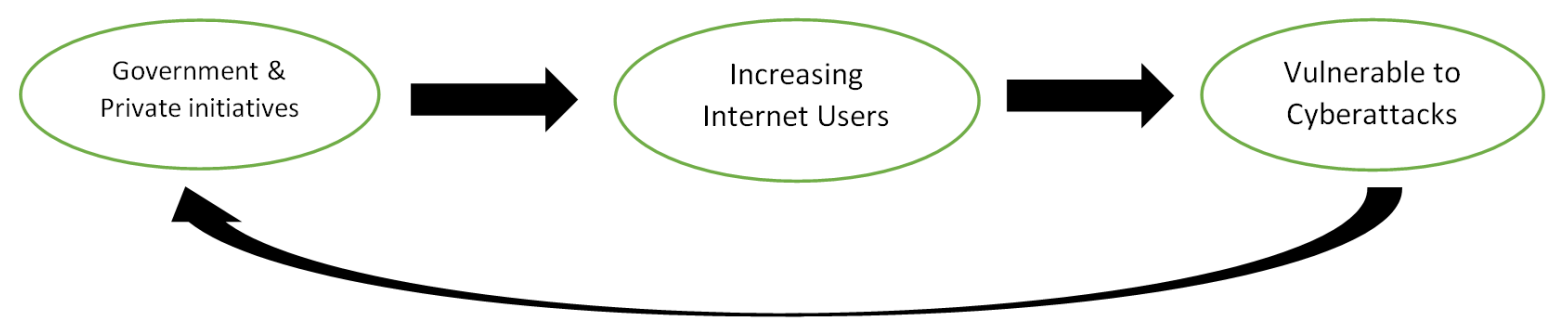




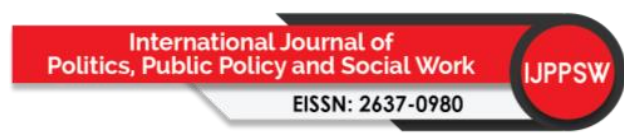

Volume 2 Issue 7 (December 2020) PP. 11-23 DOI: 10.35631/IJPPSW.27002

The increasing of internet users in South Korea has opened up the market value, emerging new business, and creates job opportunities. This shows that it does contributes on the economic sector and the South Korean government achieved its objectives by gaining more people in adopting the internet in daily life. Nevertheless, the more people are using the internet, the more exposure to cyberattacks internet users. This is because cybercriminals taking this advantage to use this platform to steal, hacking, or any cyberattacks to suit their interests. And this will reflect the South Korean government in overcoming this situation since cyber technology develops faster compared to cybersecurity, yet the government needs to keep update its policy and pursue effective implementation to manage cybersecurity.

\section{Literature Review}

\section{The South Korea National Policy in Cyber Security}

A committed government in supporting the development of internet infrastructure and high technologies are usually ending with huge opportunities. It is not only benefited its citizens but will generate the nation's income thus elevate the country's name in accepting and applying cutting-edge technologies.

To understand the cybersecurity initiatives taken by the South Korean government to compliment the demand in internet security whilst securing its national interest, we need to understand the structure organized by the country and its cooperation. South Korea introduced the National Security Strategy as a grand strategy on cybersecurity, which intends to implement initiatives taken to counter cyber threats. The objectives proposed are to build a strong cybersecurity foundation, deter, detect, and block any cyber threats, and to ensure firm operations of the state by strengthening security and resilience to enable continuous national operations (Office, 2019).

Therefore, the South Korean government has organized its structure for cyber purposes. First, the South Korea Defence White Paper mentioned about the importance of cybersecurity. For example, cybercrime will impose severe implications on the financial sector; which has affected the national economic sector as well. Furthermore, the South Korea defense white paper also recognizes the major threats received from North Korea as it repeatedly conducted illegal hacking activities towards South Korea. Overall, this defense white paper is focusing on cybersecurity to ensure cyber safety in South Korea (Office, 2019).

Meanwhile, the Korea Internet White Paper was introduced through initiatives taken by the Ministry of Science and ICT, and Korea Internet and Security Agency (KISA) to review economic and social development based on the internet usage among South Korean. Based on the history of internet users among South Korean for commercial purposed has shown acceleration of growth that turns this country as the most wired, fastest internet penetration and succeed to connect the society by commercializing the $5 \mathrm{G}$ networks. Therefore, the groundwork of internet commercializing can be used easily so that it serves as catalysts for the development of other industries such as automobile, healthcare, and finance, thus, creates innovative business and services at the same time (Seok-Hwan, 2019).

Authorities in South Korea who in charge of data protection play major roles in securing national cybersecurity. The government sector responsible for cybersecurity is the Ministry of Science and ICT, Ministry of Interior and Safety (MOIS) as well as the National Intelligence Service (NIS), and an advisor who will inform all of the cyber activities to the President. Copyright (C) GLOBAL ACADEMIC EXCELLENCE (M) SDN BHD - All rights reserved 


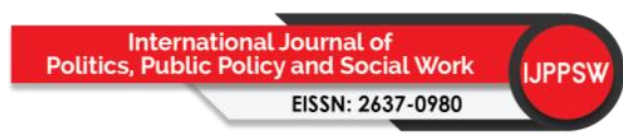

Volume 2 Issue 7 (December 2020) PP. 11-23

DOI: 10.35631/IJPPSW.27002

Besides, the South Korean government also cooperates with the private agencies whom responsible for data protection agency such as the KISA, Korea Communications Commission (KCC), Financial Services Commission (FSC) and National Human Rights Commission.

In 2011, the South Korean government has implemented a "master plan" in response to national cybersecurity by introducing a thoroughly plans with a comprehensive approach. This is crucial because the state recognizes cyberspace as a territory needing a national level defense system. Thus, the NIS runs the National Cyber Security Center (NCC) by gathering the government agencies and private sectors to encrypted and back up important data, as well as install the software as a preventive measure from cyberattacks. The master plan contains three pillars which focus on the investment on security capabilities, developments of a legal framework and to uplift international cooperation. Hence, there were 5 action plans to be carried out which are (Lewis, 2016);

1. To establish a joint response system combining the private, public, and military sectors.

2. To fortify the security of critical infrastructure and enhance secret protection.

3. To protect and blocks upon attackers at the national level.

4. To deter cyber provocations and strengthening international cooperation.

5. To build cybersecurity infrastructure.

Through this implementation, South Korea plays a crucial role in providing a safe and security in cyberspace, and encourages people to use the internet widely; thus, create a cyberculture within the boundary. Initiatives in promoting cyber culture among South Korean can be seen through the implementation of events such as the Information Security Awareness Month which is held annually. Additional efforts made by the government are organizing campaigns on the Internet Safety Keeper launched in 2013 and use celebrities as ambassadors to promote the data protection among users through media platforms such as on televisions and radios. Moreover, there were advertisements and banners were displaying on places such as subways, buses, shopping malls, and gaming halls (Lewis, 2016).

Meanwhile, since the South Korean government is an advocate in promoting internet user, it shows that broadband technology has increased with dramatic diffusion globally. Especially in the OECD countries, access to technology in the average rate of the household was around $47 \%$ in 2011 , whilst $76 \%$ of the individual has wireless broadband technology (Lee \& al, 2017). The South Korean government is known to have a robust national strategy covering broadband technology development.

Therefore, since the South Korean government made this field a free market to encourages competitor, there were several competitors which known to contributes in elevating the internet technologies such as the Korea Thrunet Co., as the first broadband serviced over proprietary cable infrastructure; Hanaro Telecom, which is the second largest provider before merged with SKT, and KT as the incumbent operator (Khayyat, 2017).

Whereas on the other, the KISA was initiated by introducing the "Cyber Vaccination Program" in collaboration with private internet service providers in helping the users to overcome cyber threats such as the botnet. The botnet is known to have the ability of denial of service attack, spam, stealing private data, and even can access the victim computers 


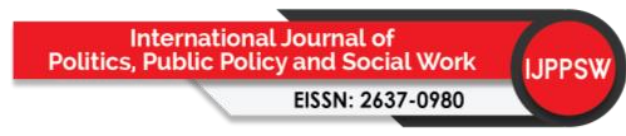

Volume 2 Issue 7 (December 2020) PP. 11-23 DOI: 10.35631/IJPPSW.27002

through hacking activities. Therefore, as the gadget has been improved from time to time and people start using smart devices, there were tools to remove malware which is known to coopt computers into networked attacks that were provided and available online for free. Meanwhile, an application was known as the Phone Keeper Apps was introduced to scan devices to detect malware threats and able to stop the users from accidentally opening links from phishing texts that lead to an infected website.

Another South Korean government's trump card in expanding internet users is through education. The university in Korea has established the Department of Cyber Defences specialized in cybersecurity to produce talents and experts in cyber, as well as provide training. This is due to the high demand for cyber competent personnel from large corporations to hire Chief Information Security Officers (Lewis, 2016).Moreover, education has proven to be a complementary action that fulfills the long term planning of the South Korean government in encouraging more internet users.

On the other, Electronics and Telecommunications Research Institute (ETRI) is an institution known to develop cutting edge technology which majorly contributes to the South Korea developments. Significant contributions of ETRI can be highlighted in 2018 when this institution developed the Tactile Internet Technology (TIC-TOC), which stands for "Time Controlled Tactile Optical Access". It is a packet-level channel bonding over multiple wavelengths and cyclic-based Dynamic Bandwidth Allocation (DBA) to support a data rate of up to $100 \mathrm{~Gb} / \mathrm{s}$ and latency less than $1 \mathrm{~ms}(\mathrm{Kim}$, et al., 2019). In simple words means it operates by transferring data packets with a minimal delay which enables it to respond with one millisecond in 5G networks. It is also able to differentiate data packets according to their respective urgency and give priority to the more urgent data packets, thus, it helps in advancing virtual reality and augmented reality in all sorts of sectors, from education, healthcare, entertainment, and public safety (Schmidt, 2019).

Based on the ETRI Report, in 2017 some of the major achievements in R\&D in technology managed to developed UHD mobile broadcasting technology and mobile hotspot networks (MHN), technology-supported with Gigabits per second (Gbps) which increase the level of data transmissions (ETRI, 2019). For example, a demonstration was done on the Seoul subway line 8 in providing a wireless backhaul data rate of Gbps for high-speed railway communication; thus, it became the first in the world of a prototype system demonstration with passengers on the train(Kim, Chung, Choi, Kim, \& Han, 2017). Whilst another major achievement in 2016, scientists from the SW EXOBRAIN, a national representative of R\&D projects on Artificial Intelligence (AI) come with another achievement in developing the language processing field. It has the ability in detecting languages through machine reading that will elevate communication skills and ease the learning process (Exobrain, 2017).

Overall, the most crucial part which improved the cybersecurity in South Korea is based on the financial support given by the South Korean government. The investment made was necessary and cooperation with local companies could bring up the cutting edge technologies which improve the nations' capabilities. Thus, with a clear objective in national policy with proper guidance and financial help does elevate the effectiveness in nurturing cyber usage among its people, public administrations, and enterprises.

Conversely, although the initiatives were taken to elevate the internet user, however, there is some weakness that the South Korean government is facing; some area has limited internet Copyright (C) GLOBAL ACADEMIC EXCELLENCE (M) SDN BHD - All rights reserved 


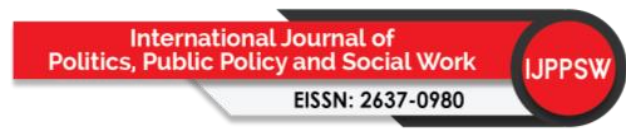

Volume 2 Issue 7 (December 2020) PP. 11-23 DOI: 10.35631/IJPPSW.27002

access due to geographical factors. To overcome this, according to the Ministry of Science and ICT stated that where ever the people are, everyone is entitled to be able to receive highspeed internet which has been designed as a universal service to meet this purpose.

Despite limitations area in receiving or restrictions of internet access such as rural and fishing communities, isolated homes and mountainous regions; the ministry has come with an initiative by giving the country's top fixed-line operator, the KT Corp to provide infrastructure in places that have the issues with internet coverage in the past. Moreover, South Korea is known to be the $8^{\text {th }}$ top in the world to offer universal high-speed internet to all citizens, with a transmission speed of $100 \mathrm{Mbps}$; the fastest speed so far(Yonhap, 2020).

\section{The Internet Users Trends among South Korea}

In accepting the internet as part of daily life means a person needs to have an inner desire to actively fulfill a need or want; which is known as the motives of internet adoption. It highlights the crucial part of an active audience with an inner drive to carry out any online activity. Besides, scholars agreed that internet users could save more energy, requires less effort or involvement physically when it comes to internet adoption (Hoffman \& Novak, 1996). Thus it is an efficient medium not only for consumers but creates opportunities for to private sector to fulfilling consumer demands through advertising the right thing. Hence this will be more compatible with the ability of the South Korean government in providing the best internet capability; easy to surf and faster internet connection.

Thus, internet policy implementation by the South Korean government shows a positive impact as the internet users increased accordingly. The price to obtain smart phones is nonetheless affordable; which almost everyone regardless of their age owns smart phones. This due to the reasons for living in the modern era, where the world becomes borderless, and smart phones' main objective is to connect the people. The internet is being used as part of daily life to contact people, using cashless transactions, mobile games, socializing through media social, and expand the business.

According to Kyung and Wong, the study has shown that the number of internet users is influenced and different based on behavior and environment such as social demographic characteristics, attitudes towards the internet, and social support (Rhee \& Kim, 2017). Hence, people who are exposed earlier with media forms are likely to accept the internet used as part of their norms. The statement supported by Rogers (1995), compatibility between innovations and existing social norms or patterns of behavior might influence the adoption of new tech, therefore people with educated, and younger are more aware of the new adapter (Rogers, 1995).

Since Kyung and Wong believe that the demographic value may affect internet adoption, a study has been conducted among the South Korean people. Thus the findings show that the highest and most frequent internet users come from the family members as they can influence themselves. Whereas the second-highest of internet users was the gender, following the marital status; thus showing that family support has an impact on internet adoption (Rhee \& Kim, 2017).

On the other, there were four types of attitudes towards internet adoption; perceived benefit, perceived negative effect, alienation from the internet and, perceived credibility. Three of the types are approving the positive value in using the internet and are ready for new Copyright (C) GLOBAL ACADEMIC EXCELLENCE (M) SDN BHD - All rights reserved 
Volume 2 Issue 7 (December 2020) PP. 11-23 DOI: 10.35631/IJPPSW.27002

technologies for upgrading, except for the 'alienation from the internet' is a type in which a person usually refuses to adopt the internet (Rhee \& Kim, 2017).

Based on a different perspective, according to a study conducted by Sylwia T. and Joanna K. (2014), South Korea is known as a well-developed country through the greatest achievement in internet infrastructure which contributes to the nation's development. Since 2013, the average connection speed for all connections in South Korea was known to be the highest global rank with 21.9 Mbps surpassing the second rank of Japan with 12.8 Mbps as shown in Figure 1(Akamai, 2013). Moreover, the internet infrastructure in South Korea was known to have the highest fiber optic penetration globally, and lead the South Korean internet users experiencing a high speed wired internet (Talar \& Kos-Labedowicz, 2014). Accordingly, the trends and internet culture among South Korean have been improved and made this country known as the most wired in the world.

\begin{tabular}{|l|l|c|c|c|}
\hline $\begin{array}{l}\text { Global } \\
\text { Rank }\end{array}$ & Country/Region & $\begin{array}{c}\text { Q1 2017 } \\
\text { Avg. Mbps }\end{array}$ & $\begin{array}{c}\text { QoQ } \\
\text { Change }\end{array}$ & $\begin{array}{c}\text { YoY } \\
\text { Change }\end{array}$ \\
\hline 1 & South Korea & 28.6 & $9.3 \%$ & $-1.7 \%$ \\
\hline 4 & Hong Kong & 21.9 & $-0.2 \%$ & $10 \%$ \\
\hline 7 & Singapore & 20.3 & $0.8 \%$ & $23 \%$ \\
\hline 8 & Japan & 20.2 & $3.1 \%$ & $11 \%$ \\
\hline 16 & Taiwan & 16.9 & $7.9 \%$ & $14 \%$ \\
\hline 21 & Thailand & 16.0 & $20 \%$ & $49 \%$ \\
\hline 27 & New Zealand & 14.7 & $14 \%$ & $40 \%$ \\
\hline 50 & Australia & 11.1 & $9.6 \%$ & $26 \%$ \\
\hline 58 & Vietnam & 9.5 & $15 \%$ & $89 \%$ \\
\hline 62 & Malaysia & 8.9 & $9.1 \%$ & $40 \%$ \\
\hline 68 & Sri Lanka & 8.5 & $17 \%$ & $58 \%$ \\
\hline 74 & China & 7.6 & $20 \%$ & $78 \%$ \\
\hline 77 & Indonesia & 7.2 & $6.7 \%$ & $59 \%$ \\
\hline 89 & India & 6.5 & $17 \%$ & $87 \%$ \\
\hline 100 & Philippines & 5.5 & $20 \%$ & $57 \%$ \\
\hline
\end{tabular}

Figure 1: Average Connection Speed (IPv4) by APAC Country/Region

Source: Talar S., Joanna K. (2014). South Korea model development of Internet economy infrastructure, ResearchGate, retrieved Jan 13, 2020, from https://www.researchgate.net/publication/282353893_South_Korea_model_of_development_of_Internet_econo my_infrastructure, p. 102.

A recent report from the Akamai in 2017, Figure 1 shows the average connection speed (IPv4) shows South Korea holds the first in global rank with Average Mbps of 28.6, surpassing China in the second rank with 21.9 Average Mbps and Singapore in the third rank with 20.3 Average Mbps. Hence, it is proven that the implementation of internet infrastructure is crucial in contributing to the speed of internet access, thus, makes the internet quality of South Korea distinct from the rest of the world. 


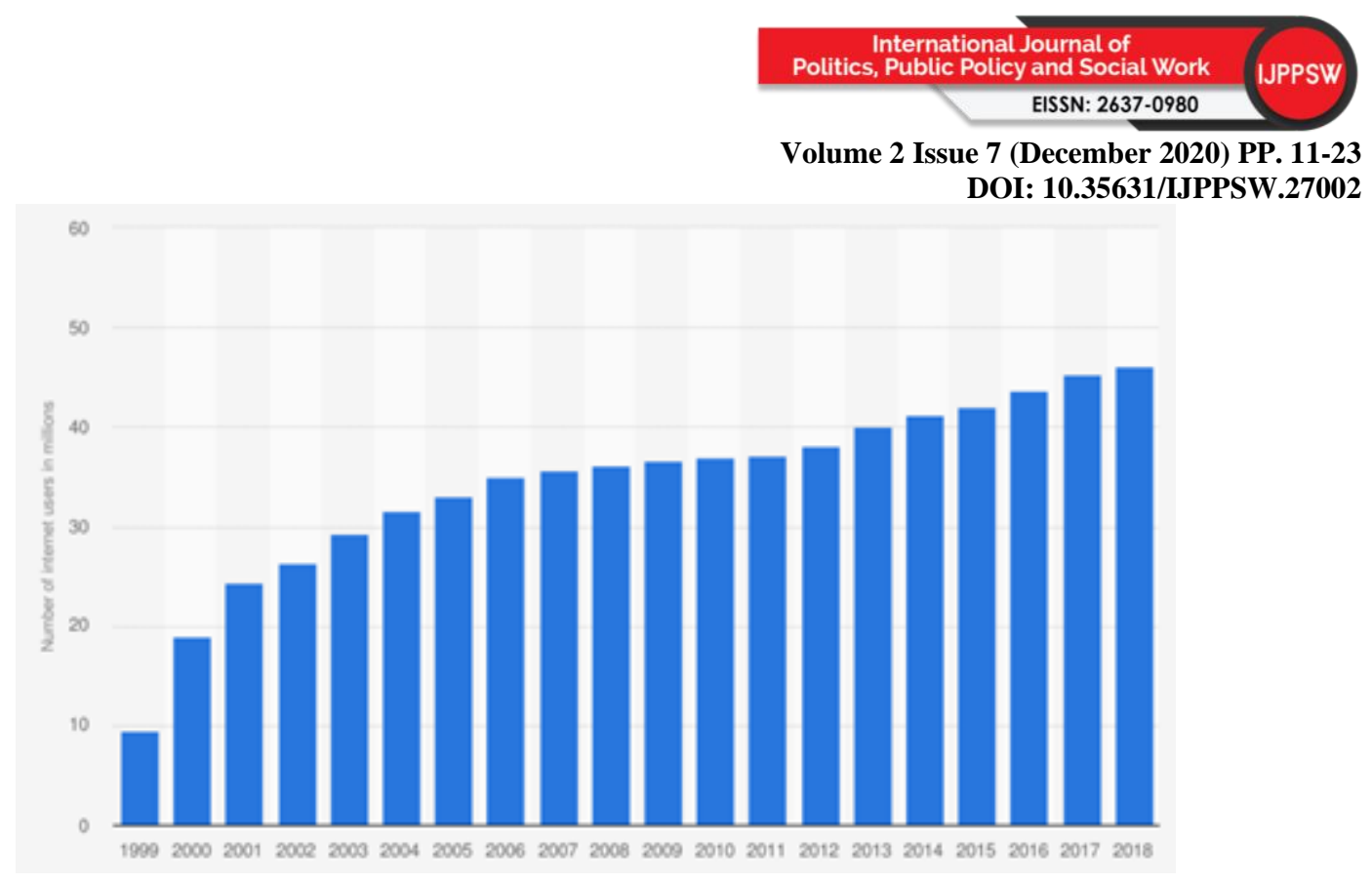

Figure 2: Number of Internet Users in South Korea from 1999 to 2018 (in mils)

Source: Market Metrix, KISA (2018). "2018 Survey on internet usage", Statista.com, retrieved March 18, 2020,from https://www.statista.com/statistics/432145/internet-users-in-south-korea/p. 25.

Apart from it, according to KISA, a survey on internet users among South Korean has been conducted by interview methods of a face-to-face interview and online survey to examine the trends of internet users. The statistics in Figure 2 shows accelerate the growth of internet introduction back in 1999 to the recent year in 2018. However, systematic policy initiatives are taken by the South Korean government in introducing the benefit of using the internet, the graph shows augment growth in 2013 where the internet users reached 40 mils. In recent year starting from 2016 to 2018, as indicated in the graph shows the gap of internet users in 2016 (43.64 mils) to 2017 (45.28 mils) was 1.64 mils increment and from 2017 to 2018 (46.13 mils), the gap was 0.85 mils (Statista, 2018).

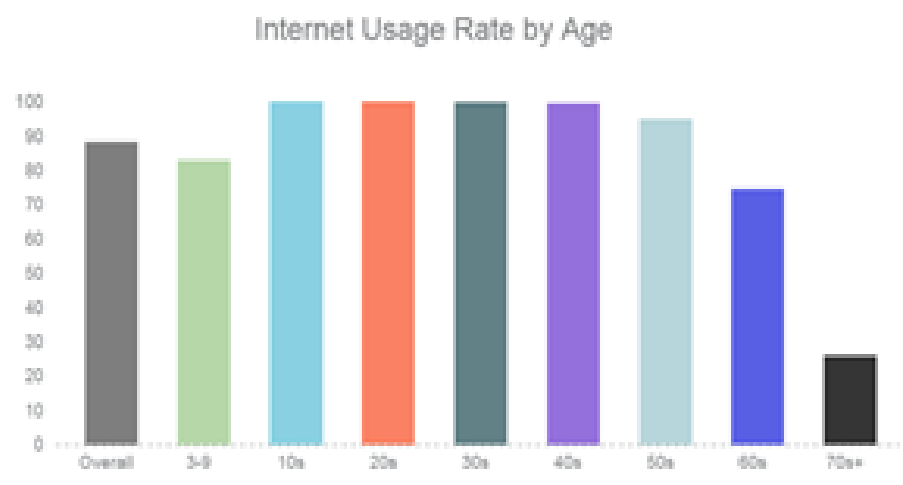

Figure 3: Internet Usage Rate by Age

Source: Ramirez E. (2017). Nearly 100\% of Households in South Korea now have Internet access, Forbes. Retrieved March 20, 2020 fromhttps://www.forbes.com/sites/elaineramirez/2017/01/31/nearly-100-ofhouseholds-in-south-korea-now-have-internet-access-thanks-to-seniors/\#3f01c865572c.

According to Ramirez E. (2017), since the South Korean government implement a wide range of $5 \mathrm{G}$ services, a survey has been made to study the trends of South Korean in accessing the internet. As shown in Figure 3, as early as age 3 are wired, which inclusive in $90 \%$ of the South Korean population in using the internet. However, the group of $10 \mathrm{~s}$, the 30s, 40s, and 50s are the dominant groups in accessing the internet. Due to the demanding 


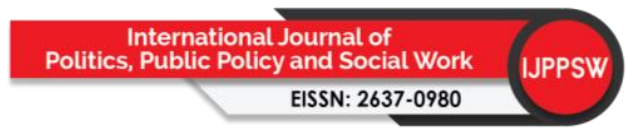

Volume 2 Issue 7 (December 2020) PP. 11-23

DOI: 10.35631/IJPPSW.27002

environment such as education purposes; information sharing, socializing, entertainment, working or it might be due to the addictiveness among users. Therefore, these people are connecting the internet via LAN, Xdsl, cable modem, mobile, and others, despite gigantic Samsung company which contributes to the exposure of internet towards the South Korean (Ramirez, 2017).

\section{The Vulnerabilities of Cybercrimes due to Internet Access in South Korea}

The challenges back in history are different from today. Back then if a person wants to steal something, he or she will go to any targeted place and do it directly, with which they are physically there to steal something. Whilst nowadays the trends of crime is different, a person who is trying to conduct a crime does not need to be there physically, it is enough with pressing a button to steal a huge amount of money from the banks, and all this is done through internet. For example, the South Korean has once experienced cyberattacks which its computer networks were paralyzed whilst running three major South Korean banks. This caused a hectic situation and many South Korean unable to withdraw money from the banks (Hun, 2013).

Therefore, since the world is getting used to cyberspace, it provides challenges to the international community based on some factors. First, cyberspace has challenged the traditional borders, and it is blurred, unlike the traditional border which separates each country. Second, it connects both the public and private sectors. Third, it collapses distance and time horizons; thus any cyberattacks may occur from any huge geographic distance, at high speed, at any time with very little warning. And forth, there are few international regulations established for cyberwar. Understandably, it is not easy to control the cyberattacks as it can happen anywhere from anyone (Borland, 2016).

The initiatives in promoting the internet by the South Korean government and other private agencies are somehow fruitful when internet users among South Korean increased to almost 100\%. Furthermore, South Korea achieved the title as the most wired country with 5G internet capability. The trends proved that South Korean implementing internet access as part of their daily life, regardless of their ages. Internet activities can be seen through surfing the internet for social activities, going cashless whilst shopping and using public transport, and business activities. This shows that the internet trend has been accepted in their socio-culture.

However, the escalation of internet access among South Korean regardless of their background identity, has engendered cybercrimes. Despite the government initiatives have taken its measure to provide safer internet access towards their people; are still unable to be stopped from spreading. Thus, it requires continuous efforts by the government and private agencies to counter cybercrimes by renewing skills and technologies to keep up with modern threats.

The cyberattack comes in two types but with one main objective which is to inflict damage on the opponents for self-interests. The two types of cyberattacks are the small-scale cyberattacks and the large-scale cyberattacks. Ever since the internet has been introduced, the frequent attack mostly comes from the small-scale attacks. This is because some people conduct cyberattacks as part of their experiments with viruses and other malicious code. The modus operandi of this crime usually has various cybercrime techniques such as shady advertising schemes, scams, or stealing money (Skoudis, 2009). 
Volume 2 Issue 7 (December 2020) PP. 11-23

DOI: 10.35631/IJPPSW.27002

On the other, large-scale cybercrimes are known to be launched by cybercriminals who have shifted from working individually to organized crime groups, or it could wage by the state actor or non-state actor. The major reason for large-scale cybercrimes is nonetheless to inflict severe damage on their victims. It could be devastated for certain countries that relied most on internet access such as South Korea (Skoudis, 2009). Examples of small-scale and largescale cyberattacks are known as below:

Small-scale cyberattacks:

- the spyware,

- bots and rootkits,

- spam,

- phishing attacks,

- credit card fraud,

- information theft,

- corporate information theft, and

- denial-of-service extortion

Large-scale cyberattacks:

- the denial-of-service packet floods,

- exploiting infrastructure components,

- damaging clients' systems with widespread botnets, and

- mass credit card fraud to disable accounts

Although cybercrimes might not be able to paralyze the whole nation, yet it could impact some of the crucial aspects such as economic capability. Especially when it comes to geographical factors since South Korea is located in strategic geography neighboring with major powers such as China, Japan, and also a rough state which is North Korea. This factor contributes to the insecurity of cybersecurity in South Korea. Therefore, cyberattacks that inflict the most damage coming from North Korea, as it claimed to be most dangerous compared to Russia.

According to Dmitri Alperovitch (2018), before launching the Crowdstrike's annual "threat report", the cyberattacks from North Korea have been increased and does not shows any slowdown progress, and this could danger other countries especially when it inflicts attack the most towards South Korea. Therefore, the report stated that "the North Korea-based adversaries are likely to continue malicious cyber activities against entities in South Korea, Japan, and the United States (US).The "threat report" from the Crowdstrike is known to be a report on the cybercrimes activities at the international level which could inflict serious damage (Hern, 2018).

On the flip side, despite having the most wired internet globally, one would need a better instrument in managing cyber threats. This is because cyber threats come in various kinds of attacks that need the right knowledge and tools to overcome them. One of the recommendations to improve cybersecurity could be done is by engaging diplomatic cybersecurity relations with major powers such as the US. This could benefit South Korea since the US has the capabilities in cyber technologies as well as its fortifying cyber policies which South Korea could review and adopt. As stated by Sangbae Kim (2015), he suggested 
that the South Korea to implement the "Brokerage Diplomacy in Cyber Security" in coordinating the South Korea relationship with other major powers in structuring the opportunities of brokerage, whilst pursuing open policy towards the United Nations (UN), the International Telecommunication Union (ITU), Organization for Economic Cooperation and Development (OECD), and Internet Corporation for Assigned Names and Numbers (ICANN); these are some parts of the recommendations to improve the South Korea cyber policy.

\section{Research Findings}

The South Korean cyber policy explanation was supported by 10 articles; National Cybersecurity Office, (2019), Lewis (2016), Seok Hwan (2019), Khayyat (2017), Schmidt (2019), ETRI (2019), Kim, K. O., et al (2019), Kim, J., et al (2017), Exobrain (2017), Yonhap (2020) in proving the initiatives by the South Korean government in strengthening and updating its cyber policy and made an effective implementation. Whereas the result for the accelerate growth number of the South Korean internet users is supported by the previous study; Hoffman \& Novak (1996), Rhee \& Kim (2017), Rogers (1995), Sylwia \& Joanna (2014), Akamai Report (2013), Talar \& Kos-Labedowicz (2014), KISA Report (2018), Ramirez E. (2017). Hence the data shown in previous literature shows the indicator for the increasing number of internet users which comes from various backgrounds and it does correlate with the speed of internet providers in South Korea. On the other, scholars recognize cyberspace as a platform to inflict damage and steal information through cyber attacks. The vulnerabilities of adopting cyberspace are supported by the previous study by Hun (2013), Borland (2016), Skoudis (2009), Hern (2018), and Sangbae Kim (2015). Scholars agreed that other than amending the cyber policy to keep update with cyber threats, South Korea is encouraged to cooperate with major cyber power such as the United States to gain benefits in strengthening its cybersecurity.

\section{Conclusion}

The world development is moving fast with the capability of internet access around the globe. Nowadays nations are competing in building their undersea cable network to dominate the internet system compared by using satellites by most countries back in time for internet purposes. Along with the improvement of internet infrastructure and other cyber technologies around the globe have enabled to utilize cyberspace.

Despite the vulnerabilities in cyber violations, the implementations of the South Korean policies in providing the best experience of internet access have succeeded with the high rate of internet users among South Korean. Based on the analysis upon relations between the government and private companies' initiatives in promoting internet usage and people in acceptance of the internet as part of daily life have benefitted the country especially for economic purposed. Moreover, the gigantic company, Samsung, is known to be the most influenced company in South Korea as it provides cutting edge technology and supports most of the national economic growth with huge profits. Thus, many advantages can be derived by the government to promote internet usage among South Korean since the economic aspect is strong to support internet policies.

\footnotetext{
1"Brokerage" referring to the role of a broker and more than a mere connector, providing a mode of transition, switching, transforming and translation between different actors in the system.

Copyright @ GLOBAL ACADEMIC EXCELLENCE (M) SDN BHD - All rights reserved
} 
On the flip side, despite having well of cyber policies, yet cybercriminals have not stopped waging the cyber threats towards the South Korean security. Since the cyber threats keep on changing in terms of its tactics, the government need to renew their cyber policies to keep up with future challenges. Therefore, the implementation by South Korea in promoting internet usage towards their people is appraisable and can be considered as a success. This is because internet usage has reached almost $100 \%$ regardless of age background; which suits the title as the most wired country in the world.

In a nutshell, this study covers some parts of the South Korean cyber policy in promoting internet users among its people and its vulnerabilities in cyber threats, hence further research may be conduct to analyze in-depth regarding the South Korean cyber policy and could be an example for another country in improving cybersecurity policy and elevate the internet users especially internet users from the area with limited internet access.

\section{References}

Akamai. (2013). Akamai's State of the Internet. Q4 2013 Report, Vol. 6, No 4. Retrieved from Akamai: from http://www.akamai.com/dl/akamai/akamai-soti-a4q413.pdf?WT.mc_id=soti_a4_Q413

Borland, N. K. (2016). Cyberwar: A Real and Growing Threat. In S. S. Costigan, \& J. Perry, Cyberspaces and Global Affairs (p. 16). New York: Routledge.

ETRI. (2019). National AI Institute Brochure. Retrieved from Electronics and Telecommunications Research Institute: https://www.etri.re.kr/engcon/sub3/sub3_0101.etri

Exobrain. (2017). Exobrain Overview. Retrieved from EXOBRAIN: http://exobrain.kr/pages/en/business/index.jsp

Hern, A. (2018, Feb 26). North Korea is a Bigger Cyber-attack Threat than Russia, Says Expert. Retrieved from The Guardian: https://www.theguardian.com/technology/2018/feb/26/north-korea-cyber-attackthreat-russia

Hoffman, D. L., \& Novak, T. P. (1996). Marketing in Hypermedia Computer-Mediated Environments: Conceptual Foundations. Journal of Marketing, 50-68.

Hun, C. S. (2013, March 20). Computer Networks in South Korea Are Paralyzed in Cyberattacks. Retrieved from The New York Times: https://www.nytimes.com/2013/03/21/world/asia/south-korea-computer-networkcrashes.html

ICT, M. o., \& KISA. (2018). Korea Internet White Paper. Seoul: Ministry of ICT of Republic of Korea.

Khayyat, N. T. (2017). A Study of Telecommunication Policies and Broadband Penetration for Sweden and South Korea. UKH Journal of Science and Engineering, Vol. 1, 29.

Kim, J., Chung, H.-S., Choi, S.-W., Kim, G. I., \& Han, Y. (2017). Mobile Hotspot Network Enhancement System for High Speed Railway Communication. European Conference on Antennas and Propagation (EUCAP) (p. 2896). Institute of Electrical and Electronics Engineers.

Kim, K. O., Doo, K.-H., Lee, H. H., Kim, S. H., Park, H., Oh, J.-Y., \& Chung, H. S. (2019). High Speed and Low Latency Passive Optical Network for 5G Wireless Systems. Journal of Lightwave Technology, Vol. 37, No 12., 2874.

Lee, S. O., \& al, E. (2017). ICT Diffusion as a determinant of human progress. Information Technology for Development, 1-19. 
Volume 2 Issue 7 (December 2020) PP. 11-23 DOI: 10.35631/IJPPSW.27002

Lewis, J. A. (2016). Advanced Experiences in Cybersecurity Policies and Practices: An Overview of Estonia, Israel, South Korea and the United States. Inter-American Development Bank, 36.

Office, N. C. (2019). National Cybersecurity Strategy. Seoul: National Cybersecurity Office.

Ramirez, E. (2017, Jan 31). Nearly 100\% Of Households In South Korea Now Have Internet Access, Thanks To Seniors. Retrieved from The Forbes: https://www.forbes.com/sites/elaineramirez/2017/01/31/nearly-100-of-households-insouth-korea-now-have-internet-access-thanks-to-seniors/\#1bffdd 225572

Rhee, K. Y., \& Kim, W. B. (2017). The Adoption and Use of the Internet in South Korea. Journal of Computer-Mediated Communication, Volume 9, Issue 4, 3.

Rogers, E. M. (1995). Diffusion of innovations (4th ed.). . New York: Free Press.

Schmidt, C. H. (2019, Jan 16). Korea Scientists bring "Tactile" Internet within reach. Retrieved from eeNews.Eurupe: https://www.eenewseurope.com/news/koreanscientists-bring-tactile-internet-within-reach

Schwab, K. (2016, Jan 14). The Fourth Industrial Revolution: What it means, how to respond. Retrieved from World Economic Forum: https://www.weforum.org/agenda/2016/01/the-fourth-industrial-revolution-what-itmeans-and-how-to-respond/.

Seok-Hwan, K. (2019). 2018 Korea Internet White Paper. Jeollanam-do: Korea Internet and Security Agency (KISA).

Skoudis, E. (2009). Information Security Issues in Cyberspace. In F. D. Kramer, S. H. Starr, \& L. K. Wentz, Cyberpower and National Security (pp. 172-187). Washington DC: National Defense University Press.

Statista. (2018). 2018 Survey on Internet Usage. Retrieved from Statista.com: https://www.statista.com/statistics/432145/internet-users-in-south-korea/

Talar, S., \& Kos-Labedowicz, J. (2014). South Korea Model Development of Internet Economy Insfrastructure. Research Gate, 102.

Yonhap. (2020, Jan 05). S. Korea starts universal super high-speed internet service for entire country. Retrieved from Korea Herald: http://www.koreaherald.com/view.php?ud=20200105000109 